\title{
ST-elevation Myocardial Infarction in Over 100 Years Old Patient: What is The Better Option?
}

\author{
Ilma Alfia Isaridha ${ }^{a}$, Budi Susetyo Pikir ${ }^{b^{*}}$ \\ a ilmaalfia@gmail.com \\ ${ }^{\text {a}}$ Faculty of Medicine, Universitas Airlangga, Prof Moestopo Street 6-8, Surabaya 60286, Indonesia \\ ${ }^{b}$ Department of Cardiology and Vascular Medicine, Faculty of Medicine, Universitas Airlangga, Prof Moestopo \\ Street 6-8, Surabaya 60286, Indonesia
}

\begin{abstract}
Background: Optimal therapy in ST-elevation myocardial infarction (STEMI) patients with extreme age is still a challenge. The presence of comorbidities and multiorgan dysfunction simultaneously increases the risk of ischemia and bleeding. Unfortunately, there are no adequate data for the benefit and reliability of the treatment in elderly patients.

Case Summary: We report a case of a 103-year-old patient with substernal chest pain 6 hours before admission. His medical history was unremarkable. The physical examination revealed irregularly irregular pulse. An electrocardiogram showed atrial fibrillation with a moderate ventricular response with ST-elevation and $\mathrm{Q}$ waves in inferior lead. The patient was treated conservatively with dual antiplatelet aspirin and clopidogrel, and anticoagulated with fondaparinux. Although medical management was carried out because of family concerns, the best choice of therapy for STEMI patients of extreme ages was still a question.

Discussion: Current practice guidelines recommend primary percutaneous coronary intervention as therapy of choice in STEMI patients with no upper age limit, and to start dual antiplatelet therapy using aspirin and a $\mathrm{P}_{2} \mathrm{Y}_{12}$ receptor blocker in all patients including the elderly. In a patient with atrial fibrillation, a shorter duration of dual antiplatelet therapy is recommended. Data regarding reperfusion therapy with the best level of efficacy and safety in this group is limited. Trials comparing various treatment strategies with oral anticoagulants are designed to investigate the safety, rather than efficacy. Another option to use single antiplatelet therapy to minimize bleeding risk still has limited data.
\end{abstract}

Keywords: myocardial infarction, elderly, extreme age

Keywords: myocardial infarction; elderly; extreme age

\section{Introduction}

The incidence of acute coronary syndrome (ACS) increases with age, including in the elderly. This elderly age group has a high risk both in terms of bleeding and ischemic events. Under these circumstances, the optimal strategy in the management of elderly patients with ACS is still a question, where the benefits of invasive strategies on ischemic outcomes must be balanced with the risks related to antithrombotic therapy 
and percutaneous coronary intervention (PCI). Antiplatelet therapy can be a double-edged sword that reduces the risk of ischemic events but expose the elderly patient to increased risk of major bleeding (Lattuca et al., 2019).

The increasing incidence and magnitude of risk in elderly patients is not in line with existing therapeutic data. Inadequate representation of this group in randomized studies results in a lack of knowledge regarding optimal care for this age group. The lack of evidence from randomized studies of interventions and antithrombotics is due to the selection of patients with low bleeding risk and not included the elderly patients (Alexander et al., 2007; Lee et al., 2001).

\section{Case Report}

We reported a case of a man, 103 years old, who came with the chief complaint of a heavy feeling in the middle of his chest in the past 6 hours before admission. There were no complaints of shortness of breath or palpitation. Past medical history did not reveal hypertension, diabetes mellitus, or hypercholesterolemia. The patient smoked when he was young but had long since he quit. There is no family history of heart disease.

Physical examination revealed that the patient was compos mentis with blood pressure $113 / 60 \mathrm{mmHg}$, pulse rate of 100x/minute irregularly irregular, respiratory rate 20x/minute with oxygen saturation of $98 \%$ with nasal oxygen. The pain scale on arrival is five out of ten. Thoracic examination revealed irregularly irregular heart sounds, no murmurs were found. Pulmonary examination revealed no crackles or wheezing. Other physical examinations were within normal limits.

Electrocardiographic examination (Fig. 1) revealed atrial fibrillation rhythm with an average ventricular response of 120x/min, frontal axis deviation to the left, horizontal axis rotation clockwise, ST elevation with $\mathrm{T}$ inversion in leads II, III, aVF was obtained. Laboratory examination showed white blood cell count increased 14.120, creatinine serum decreased 1.6 milligrams/deciliters with estimated glomerular filtration rate 34 milliliters/minute/1.73 m2, low potassium 3.4 millimoles/liters, low albumin 2.5 gram/deciliters, and Troponin-I 4 nanogram/milliliters. Other laboratory examinations were within normal limits.

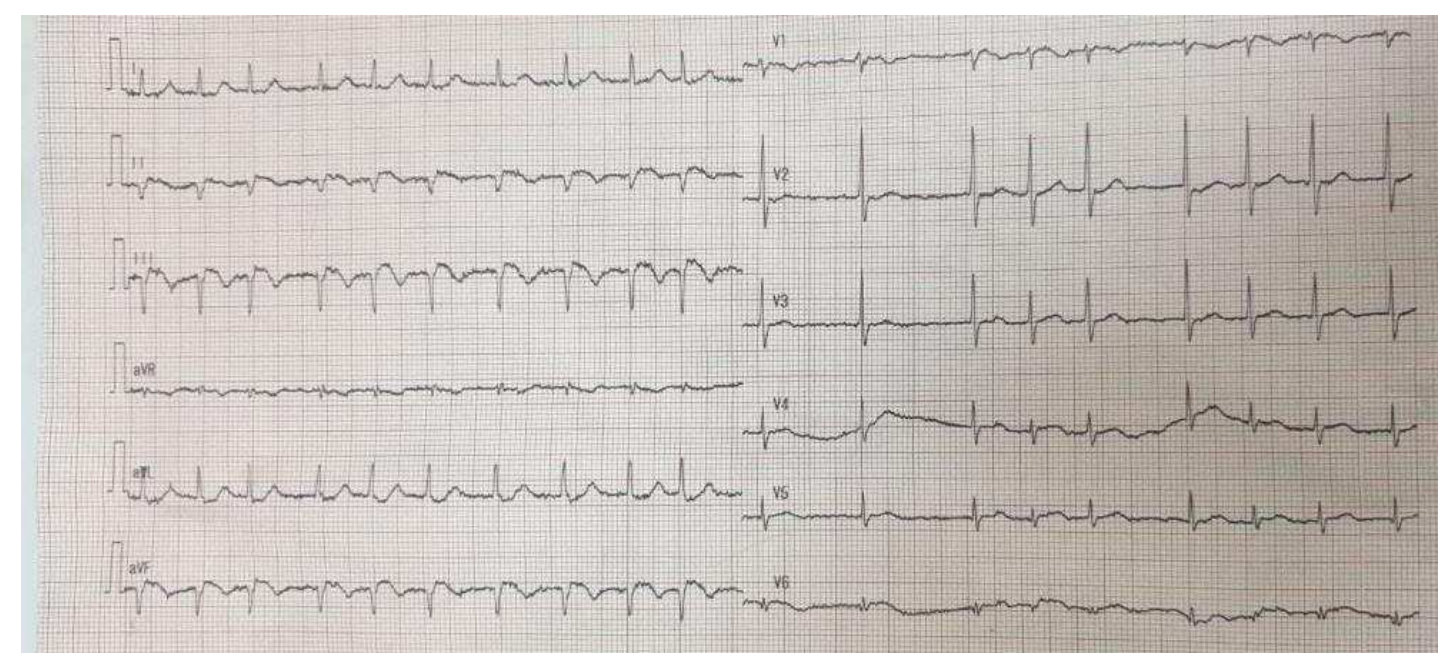

Figure 1. Electrocardiography of a patient with ST-elevation and T inversion in inferior lead

Examination of the chest $\mathrm{x}$-ray appears to be lacking inspiration with a normal impression of the heart. Examination of echocardiography showed mild aortic regurgitation, normal chamber dimension, preserved left 
ventricular systolic function with ejection fraction 53\%, and hypokinetic at inferior basal and mid segments. The patient was admitted to the intensive care unit and treated conservatively with medical management with aspirin 100 milligrams, clopidogrel 75 milligrams, atorvastatin 40 milligrams, bisoprolol 2.5 milligrams and, fondaparinux injection 2.5 milligrams subcutaneously. During hospitalization, there was no bleeding complication and the patient was discharged with a single antiplatelet and oral anticoagulant regimen.



Figure 2. Chest X-Ray of the patient

\section{Discussion}

The 2017 European Society of Cardiology guidelines states that patients with ST-elevation acute myocardial infarction (STEMI), with symptom onset less than 12 hours, are recommended for reperfusion therapy. If the PCI procedure can be performed within 2 hours, reperfusion with primary PCI is preferred. The guidelines also state that reperfusion therapy options have no age limit (Ibanez et al., 2018). This means that in the elderly, including the extreme age group, reperfusion therapy with primary PCI is still recommended.

National registry data in England and Wales, the Myocardial Ischaemia National Audit Project (MINAP) stated that elderly patients tend to be less likely to receive invasive management in STEMI cases. In the 85year age group, only $55 \%$ of patients received reperfusion therapy, compared with $84 \%$ in the $18-65$-year age group. Survival rates were lower in patients who did not receive intensive therapy in all age groups, although the mortality benefit decreased gradually with age (Justin Zaman et al., 2014). In everyday practice, therapeutic decisions are usually based on a patient-centered approach that combines evaluation of the patient's debilitating condition, including functional or cognitive status and life expectancy and a balance between bleeding and ischemic risk.

Several studies have shown that performing invasive strategies in patients 85 years of age provides an advantage in terms of angiographic success, and two to three-fold lower in-hospital and 12-month mortality rates compared with those treated conservatively (Helft et al., 2015; Mandawat et al., 2013; Yudi et al., 2016). A study in Poland also demonstrated the benefit of invasive therapy in patients over 100 years of age (Piegza et al., 2020). 
Fibrinolytic therapy is an important reperfusion strategy in situations where primary PCI cannot be performed promptly. Thrombolytic therapy provides an advantage in terms of mortality, including in the elderly age group where the mortality rate is significantly reduced in patients aged 75 years who receive thrombolytic therapy from $29.4 \%$ to $26.0 \%$. The absolute reduction in mortality in patients 75 years of age was 34 lives saved per 1000 patients (White, 2000).

Comparison of reperfusion therapy with primary PCI and fibrinolytics was carried out by the TRIANA trial (TRatamiento del Infarto Agudo de miocardio eN Ancianos). Results showed no significant reduction was found in mortality, re-infarction, or stroke. A combined analysis with two previous reperfusion trials demonstrated an advantage of primary PCI over fibrinolysis in reducing mortality, re-infarction, or stroke at 30 days. Only four strokes occurred in the fibrinolytic group and none of them were initially hemorrhagic (Bueno et al., 2011).

The benefits of fibrinolytic need to be weighed against the risk of bleeding. In the study ASSENT-2 stated that any increase in the age of 10 years is associated with a risk of intracranial and non-intracranial bleeding $63 \%$ and $40 \%$ higher. However, patients treated with tenecteplase were less likely to have a major bleeding event than those treated with alteplase. This difference was found across subgroups with different levels of risk but is especially noticeable in elderly patients (Van De Werf et al., 2001).

In the STREAM trial (Strategic Early Reperfusion after Myocardial Infarction), after approximately onefifth of the population has registered, the bolus tenecteplase was reduced by half in patients aged $\geqslant 75$ years due to a high incidence of intracranial hemorrhage. Before the reduced dose tenecteplase, 3 of $42(7.1 \%)$ of elderly patients treated with fibrinolytic experiencing intracranial bleeding, and two of them had a fatal complication (Armstrong et al., 2015). After a dose reduction was implemented in the STREAM trial, none of intracranial hemorrhage or stroke were observed in patients aged $\geqslant 75$ years.

In the case illustration above, the patient received conservative therapy due to the absence of an available PCI center and family concerns. However, the data and guidelines still recommend primary PCI as the main reperfusion therapy in elderly patients. The radial route is preferred in elderly patients due to a reduction in mortality and bleeding rates compared to the femoral route (Ibanez et al., 2018).

Dual antiplatelet therapy with aspirin plus $\mathrm{P}_{2} \mathrm{Y}_{12}$ inhibitor is the main treatment of ACS patients. Prasugrel and ticagrelor show better effect in reducing ischemic endpoints compared with clopidogrel in large randomized trials but the benefit/risk ratio of intense platelet inhibition in elderly patients is debated, and clopidogrel is still widely used (Lattuca et al., 2019). However, international guidelines recommend ticagrelor as first-line therapy regardless of age (Ibanez et al., 2018). The European Society of Cardiology recommends ticagrelor in elderly acute coronary syndrome patients in the absence of contraindications such as active bleeding or previous intracranial hemorrhage, with caution in those with advanced sinoatrial disease who are not treated with permanent pacemakers and in those who have a history of asthma and/or chronic obstructive pulmonary disease (Andreotti et al., 2015). Prasugrel $10 \mathrm{mg}$ administration is not recommended in patients $\geqslant$ 75 years of age, because it is not associated with an increased clinical benefit (Wiviott et al., 2011). Even if a reduced dose of $5 \mathrm{mg}$ is indicated, the efficacy and safety of this dose compared with clopidogrel is debatable. Prasugrel is also not recommended in conservatively treated elderly ACS patients (Roe et al., 2013).

In patients receiving fibrinolytic, it is not known whether clopidogrel loading in the elderly who get thrombolytic therapy is safe, so clopidogrel loading cannot be recommended in the elderly group. In patients undergoing fibrinolytic therapy, clopidogrel is administered at a dose of $75 \mathrm{mg}$ before fibrinolytic therapy. An anticoagulant dose adjustment of enoxaparin was administered without an intravenous bolus if the patient was on thrombolytics and was continued with a daily dose of $0.75 \mathrm{mg} / \mathrm{kg}$ body weight (Andreotti et al., 2015).

In selecting the appropriate antiplatelet therapy, one must first consider the risk of bleeding before the risk of ischemic. Bleeding risk is assessed according to the Academic Research Consortium of High Bleeding Risk and PRECISE-DAPT score (Collet et al., 2021; Valgimigli et al., 2018). Several attempts can be made in the 
use of antiplatelets to minimize the risk of bleeding in elderly patients. After assessing the risk of bleeding, then antiplatelet can be chosen whether to give a potent or less potent $\mathrm{P}_{2} \mathrm{Y}_{12}$ inhibitor. Ticagrelor may be considered in non-high bleeding risk patients. If ticagrelor is chosen, consider to discontinue aspirin 3 months post-STEMI. Another strategy is to deescalate $\mathrm{P}_{2} \mathrm{Y}_{12}$ inhibitors from potent to less potent, 30 days after the events (Capranzano and Angiolillo, 2021). In patients who indicate anticoagulation, the $\mathrm{CHA}_{2} \mathrm{DS}_{2}-\mathrm{VASc}$ score should be assessed. In the case of patients who need anticoagulation, clopidogrel is the $\mathrm{P}_{2} \mathrm{Y}_{12}$ inhibitor of choice and the use of proton pump inhibitors should be considered (Valgimigli et al., 2018). Based on the criteria of the Academic Research Consortium of High Bleeding Risk, the patient in this case was included in the high bleeding risk because of a rhythm disturbance that required long-term anticoagulant therapy. In this case, triple antiplatelet therapy can be given for 1 week followed by a single antiplatelet and anticoagulant (Collet et al., 2021).

\section{Conclusion}

Elderly patients with STEMI should receive the same recommended therapy as younger patients. Invasive strategies are an option if they can be implemented promptly, although it is important to assess functional and cognitive status first. Fibrinolytics are an alternative to reperfusion when primary PCI cannot be performed. Strategies to reduce the risk of bleeding include a radial approach and adjustment of dose and duration of antithrombotic and anticoagulant as indicated.

\section{Conflict of Interest}

The authors declare no conflict of interest.

\section{References}

Alexander, K.P., Newby, L.K., Armstrong, P.W., Cannon, C.P., Gibler, W.B., Rich, M.W., Van De Werf, F., White, H.D., Weaver, W.D., Naylor, M.D., Gore, J.M., Krumholz, H.M., Ohman, E.M., 2007. Acute coronary care in the elderly, part II: ST-segmentelevation myocardial infarction: A scientific statement for healthcare professionals from the American heart association council on clinical cardiology. Circulation 115, 2570-2589. https://doi.org/10.1161/CIRCULATIONAHA.107.182616

Andreotti, F., Rocca, B., Husted, S., Ajjan, R.A., Berg, J. Ten, Cattaneo, M., Collet, J.P., Caterina, R. De, Fox, K.A.A., Halvorsen, S., Huber, K., Hylek, E.M., Lip, G.Y.H., Montalescot, G., Morais, J., Patrono, C., Verheugt, F.W.A., Wallentin, L., Weiss, T.W., Storey, R.F., 2015. Antithrombotic therapy in the elderly: Expert position paper of the European society of cardiology working group on thrombosis. Eur. Heart J. 36, 3238-3249. https://doi.org/10.1093/eurheartj/ehv304

Armstrong, P.W., Zheng, Y., Westerhout, C.M., Rosell-Ortiz, F., Sinnaeve, P., Lambert, Y., Lopes, R.D., Bluhmki, E., Danays, T., Van De Werf, F., 2015. Reduced dose tenecteplase and outcomes in elderly ST-segment elevation myocardial infarction patients: Insights from the STrategic Reperfusion Early after Myocardial infarction trial. Am. Heart J. 169, 890-898.e1. https://doi.org/10.1016/j.ahj.2015.03.011

Bueno, H., Betriu, A., Heras, M., Alonso, J.J., Cequier, A., García, E.J., López-Sendón, J.L., MacAya, C., Hernández-Antolín, R., 2011. Primary angioplasty vs. fibrinolysis in very old patients with acute myocardial infarction: TRIANA (TRatamiento del Infarto Agudo de miocardio en Ancianos) randomized trial and pooled analysis with previous studies. Eur. Heart J. 32, 51-60. https://doi.org/10.1093/eurheartj/ehq375

Capranzano, P., Angiolillo, D.J., 2021. Antithrombotic Management of Elderly Patients With Coronary Artery Disease. JACC Cardiovasc. Interv. 14, 723-738. https://doi.org/10.1016/j.jcin.2021.01.040

Collet, J.P., Thiele, H., Barbato, E., Bauersachs, J., Dendale, P., Edvardsen, T., Gale, C.P., Jobs, A., Lambrinou, E., Mehilli, J., Merkely, B., Roffi, M., Sibbing, D., Kastrati, A., Mamas, M.A., Aboyans, V., Angiolillo, D.J., Bueno, H., Bugiardini, R., Byrne, R.A., Castelletti, S., Chieffo, A., Cornelissen, V., Crea, F., Delgado, V., Drexel, H., Gierlotka, M., Halvorsen, S., Haugaa, K.H., Jankowska, E.A., Katus, H.A., Kinnaird, T., Kluin, J., Kunadian, V., Landmesser, U., Leclercq, C., Lettino, M., Meinila, L., Mylotte, D., Ndrepepa, G., Omerovic, E., Pedretti, R.F.E., Petersen, S.E., Petronio, A.S., Pontone, G., Popescu, B.A., Potpara, T., Ray, K.K., Luciano, F., Richter, D.J., Shlyakhto, E., Simpson, I.A., Sousa-Uva, M., Storey, R.F., Touyz, R.M., Valgimigli, M., Vranckx, P., Yeh, R.W., Barthélémy, O., Bhatt, D.L., Dorobantu, M., Folliguet, T., Gilard, M., Jüni, P., Lewis, B.S., Meliga, E., Mueller, C., Rutten, F.H., Siontis, G.C.M., 2021. 2020 ESC Guidelines for the management of acute coronary syndromes in patients presenting without persistent ST-segment elevation. Eur. Heart J. 42, 1289-1367. 
https://doi.org/10.1093/eurheartj/ehaa575

Helft, G., Georges, J.L., Mouranche, X., Loyeau, A., Spaulding, C., Caussin, C., Benamer, H., Garot, P., Livarek, B., Teiger, E., Varenne, O., Monségu, J., Mapouata, M., Petroni, T., Hammoudi, N., Lambert, Y., Dupas, F., Laborne, F., Lapostolle, F., Lefort, H., Juliard, J.M., Letarnec, J.Y., Lamhaut, L., Lebail, G., Boche, T., Jouven, X., Bataille, S., 2015. Outcomes of primary percutaneous coronary interventions in nonagenarians with acute myocardial infarction. Int. J. Cardiol. 192, 24-29. https://doi.org/10.1016/j.ijcard.2015.04.227

Ibanez, B., James, S., Agewall, S., Antunes, M., Al, E., 2018. 2017 ESC Guidelines for the management of acute myocardial infarction in patients presenting with ST -segment elevation The Task Force for the management of acute myocardial infarction 119-177. https://doi.org/10.1093/eurheartj/ehx393

Justin Zaman, M., Stirling, S., Shepstone, L., Ryding, A., Flather, M., Bachmann, M., Myint, P.K., 2014. The association between older age and receipt of care and outcomes in patients with acute coronary syndromes: A cohort study of the Myocardial Ischaemia National Audit Project (MINAP). Eur. Heart J. 35, 1551-1558. https://doi.org/10.1093/eurheartj/ehu039

Lattuca, B., Kerneis, M., Zeitouni, M., Cayla, G., Guedeney, P., Philippe, J., Montalescot, G., Silvain, J., 2019. Elderly Patients with ST Segment Elevation Myocardial Infarction : A Patient - Centered Approach 40266.

Lee, P.Y., Alexander, K.P., Hammill, B.G., Pasquali, S.K., Peterson, E.D., 2001. Representation of elderly persons and women in published randomized trials of acute coronary syndromes. J. Am. Med. Assoc. 286, 708-713. https://doi.org/10.1001/jama.286.6.708

Mandawat, Aditya, Mandawat, Anant, Mandawat, M.K., 2013. Percutaneous coronary intervention after ST-segment elevation myocardial infarction in nonagenarians: Use rates and in-hospital mortality. J. Am. Coll. Cardiol. 61, 1207-1208. https://doi.org/10.1016/j.jacc.2012.12.019

Piegza, J., Poloński, L., Desperak, A., Wester, A., Janion, M., Mazurek, W., Wojakowski, W., Witkowski, A., Dudek, D., Gąsior, M., 2020. Myocardial Infarction in Centenarians. Data from The Polish Registry of Acute Coronary Syndromes. J. Clin. Med. 9, 3377. https://doi.org/10.3390/jcm9103377

Roe, M.T., Goodman, S.G., Ohman, E.M., Stevens, S.R., Hochman, J.S., Gottlieb, S., Martinez, F., Dalby, A.J., Boden, W.E., White, H.D., Prabhakaran, D., Winters, K.J., Aylward, P.E., Bassand, J.P., McGuire, D.K., Ardissino, D., Fox, K.A.A., Armstrong, P.W., 2013. Elderly patients with acute coronary syndromes managed without revascularization: Insights into the safety of long-term dual antiplatelet therapy with reduced-dose prasugrel versus standard-dose clopidogrel. Circulation 128, 823-833. https://doi.org/10.1161/CIRCULATIONAHA.113.002303

Valgimigli, M., Bueno, H., Byrne, R.A., Collet, J.P., Costa, F., Jeppsson, A., Jüni, P., Kastrati, A., Kolh, P., Mauri, L., Montalescot, G., Neumann, F.J., Petricevic, M., Roffi, M., Steg, P.G., Windecker, S., Zamorano, J.L., Badimon, L., Ibanez, B., Vranckx, P., Pierard, L., Van de Werf, F., Agewall, S., Andreotti, F., Barbato, E., Bugiardini, R., De Bonis, M., Galiè, N., Lettino, M., Piepoli, M.F., Stabile, E., Antman, E., Bassand, J.P., Cuisset, T., Gilard, M., Iung, B., Leclercq, C., Aboyans, V., Cikirikcioglu1, M., Gaemperli, O., Schwerzmann, M., Delgado, V., Verheugt, F., Fitzsimons, D., Lip, G., Simpson, I.A., Storey, R.F., Hamm, C.W., Landmesser, U., Sechtem, U., James, S., Knuuti, J., SousaUva1, M., Tendera, M., 2018. 2017 ESC focused update on dual antiplatelet therapy in coronary artery disease developed in collaboration with EACTS. Eur. J. Cardio-thoracic Surg. 53, 34-78. https://doi.org/10.1093/ejcts/ezx334

Van De Werf, F., Barron, H. V., Armstrong, P.W., Granger, C.B., Berioli, S., Barbash, G., Pehrsson, K., Verheugt, F.W.A., Meyer, J., Betriu, A., Califf, R.M., Li, X., Fox, N.L., 2001. Incidence and predictors of bleeding events after fibrinolytic therapy with fibrinspecific agents: A comparison of TNK-tPA and rt-PA. Eur. Heart J. 22, 2253-2261. https://doi.org/10.1053/euhj.2001.2686

White, H.D., 2000. Thrombolytic therapy in the elderly. Lancet 356, 2028-2030.

Wiviott, S.D., Desai, N., Murphy, S.A., Musumeci, G., Ragosta, M., Antman, E.M., Braunwald, E., 2011. Efficacy and safety of intensive antiplatelet therapy with prasugrel from TRITON-TIMI 38 in a core clinical cohort defined by worldwide regulatory agencies. Am. J. Cardiol. 108, 905-911. https://doi.org/10.1016/j.amjcard.2011.05.020

Yudi, M.B., Jones, N., Fernando, D., Clark, D.J., Ramchand, J., Jones, E., Dakis, R., Johnson, D., Chan, R., Islam, A., Farouque, O., Horrigan, M., 2016. Management of patients aged $\geq 85$ years with ST-elevation myocardial infarction. Am. J. Cardiol. 118, 44-48. https://doi.org/10.1016/j.amjcard.2016.04.010 